\title{
\begin{tabular}{|l|} 
EXPERT \\
REVIEWS
\end{tabular}
}

\section{New evidence for nicotinic acid treatment to reduce atherosclerosis}

Expert Rev. Cardiovasc. Ther. 8(10), 1457-1467 (2010)

\section{Fabrizio Montecucco ${ }^{+1}$, Alessandra Quercioli', Franco Dallegri², Giorgio Luciano Viviani ${ }^{3}$ and François Mach ${ }^{1}$}

'Cardiology Division, Department of Medicine, Geneva University Hospital, Foundation for Medical Research, 64 Avenue Roseraie, 1211 Geneva, Switzerland

${ }^{2}$ Clinic of Internal Medicine I, University of Genoa, Viale Benedetto XV 6, 16132 Genoa, Italy ${ }^{3}$ Geriatric Division, Department of Internal Medicine, University of Genoa, Viale Benedetto XV 6,

16132 Genoa, Italy ${ }^{\dagger}$ Author for correspondence:

Tel.: +41223827238

Fax: +41223827245

fabrizio.montecucco@unige.ch

Nicotinic acid (at a daily dose of grams) has been shown to induce potent antiatherosclerotic effects in human and animal models. Evidence from clinical studies performed in the 1950s has shown that nicotinic acid treatment remarkably improves the plasma lipid profile. Large clinical studies showed that nicotinic acid improves clinical cardiovascular outcomes. Given the protective effects of niacin, basic research studies were designed to explore additional antiatherosclerotic pathways, such as those involved in cardiovascular inflammation. After the discovery of the nicotinic acid receptor GPR109A on adipocytes and immune cells, novel direct immunomodulatory properties of nicotinic acid have been identified. Importantly, the regulation of the release of inflammatory mediators from adipose tissue was observed, independent of lipid level amelioration. Less is known about the possible direct anti-inflammatory activities of nicotinic acid in other cells (such as hepatocytes, endothelial and vascular cells) previously indicated as key players in atherogenesis. Thus, further studies are needed to clarify this promising topic. Emerging evidence from clinical and basic research studies indicates that novel direct antiatherosclerotic properties might mediate nicotinic acid-induced cardiovascular protection. Despite some limitations in its clinical use (mainly due to the incidence of adverse events, such as cutaneous flushing and hepatotoxicity), nicotinic acid should be considered as a very potent therapeutic approach to reduce atherosclerosis. Promising research developments are warranted in the near future.

KEYWORDS: atherosclerosis $\bullet$ cardiovascular risk $\bullet$ cholesterol $\bullet$ inflammation $\bullet$ nicotinic acid

Niacin is a water-soluble vitamin (vitamin $\mathrm{B}_{3}$ ) abundant in meat, eggs, fish, dairy and vegetables [1]. Its deficiency causes pellagra, a disease characterized by dermatitis, diarrhea and dementia. Niacin is a fundamental precursor of the coenzymes nicotinamide adenine dinucleotide (NAD) and NAD phosphate (NADP), which play a crucial role in the chemical reactions underlying the normal functions and survival of different cell types. Nicotinic acid and nicotinamide have been interchangeably termed as 'niacin equivalents' [2]. Only the administration of high doses ( $2 \mathrm{~g} /$ day $)$ of nicotinic acid has been shown to improve lipid profile, but this can also induce unwanted effects, such as cutaneous flushing [3]. Although low doses ( $15 \mathrm{mg} /$ day $)$ of nicotinamide are recommended to reduce the risk of pellagra [4], high doses ( $\sim \mathrm{g} /$ day) are not well tolerated and require medical supervision [5]. Furthermore, differently from nicotinic acid, high doses of nicotinamide do not improve lipid profile [6].
Thus, among niacin equivalents, nicotinic acid is the most widely investigated beneficial molecule in cardiovascular disease and lipid management. Despite evidence from basic research and clinical studies, the molecular mechanisms underlying its protective and adverse effects remain unclear. Even less is known about possible niacin-mediated direct pleiotropic and anti-inflammatory activities. Interestingly, the recent demonstration of possible nicotinic acid receptors (orphan G-proteincoupled receptors named GPR109A [high affinity, mouse PUMA-G equivalent] and GPR109B [low affinity]) on adipocytes and immune cells may have promising implications for developments in atherosclerosis [7-9]. However, since GPR109B was activated only at extremely high concentrations $\left(\mathrm{EC}_{50}\right.$ values are in excess of $1 \mathrm{mM}$ ) that are not reached in the plasma even after very high doses, GPR109A is considered the most important receptor of nicotinic acid. In this article, we will update research evidence 
exploring the therapeutic potential of nicotinic acid in the regulation of atherosclerotic inflammation, also independently of lipid profile improvement.

\section{Niacin-mediated adverse effects}

Daily gram quantities of niacin produce not only marked benefits on lipid profile and atherogenic dyslipidemia, but also significant adverse events, mainly owing to drug formulation and metabolism [10-12]. Glycine conjugation of niacin to produce nicotinuric acid was initially associated with cutaneous flushing, localized in the upper body and face [13]. However, this first hypothesis, never based on very solid data, has been recently updated. Niacin-induced flushing was shown to be mainly mediated by the GPR109 nicotinic acid receptor and release of vasodilatory prostanoids $[8,14]$. Immediate-release niacin preparation has mainly been associated with cutaneous flushing and extended-release preparations have been shown to induce modest alterations of levels of alanine aminotransferase (ALT) and aspartate aminotransferase (AST) [15-17]. Importantly, cutaneous flushing limits the therapeutic use of niacin. A large amount of patients $(\sim 70-80 \%)$ has been shown to suffer from this adverse effect mainly during the first weeks of treatment [18]. Flushing tends to be reduced after several weeks of stable therapy and in the presence of extended-release niacin formulations $[19,20]$. Although the total dose of niacin was similar in both preparations, the different adverse effects could be mediated by the plasma concentration peak of niacin and nicotinuric acid during early hours. New extended-release formulations have been designed to obtain an optimal balance between the niacin metabolic pathways [21]. Despite these efforts, the reduction of flushing response during extended-release niacin treatment was still modest. However, a selective antagonist of the DP1 receptor (laropiprant, MK-0524) has been shown to strongly reduce niacin-mediated flushing in both human and animal studies [22-24]. Combination treatments with high doses of extendedrelease niacin with laropiprant $(30-300 \mathrm{mg} /$ day) significantly reduced flushing-induced therapy discontinuation in dyslipidemic patients compared with niacin alone (10.2 vs 22\%) [25]. Laropiprant did not affect niacin-mediated benefits on lipid profile [26]. Preliminary results on hepatotoxicity have also been reported during treatment with niacin/laropiprant. No significant increase in ALT and AST levels or drug-induced hepatitis incidence was observed by Paolini and coworkers in the overall population pooled from three active or placebo-controlled Phase III studies and three Phase II 1-year safety extension studies [27]. In addition, no increase in ALT or AST levels was observed in combination 12 -week treatments with different doses of niacin/laropiprant and simvastatin in patients with primary hypercholesterolemia or mixed hyperlipidemia [28] Following approval by the European Medicines Agency, extended-release niacin in combination with laropiprant is available on the market in several countries. The first clinical studies using niacin/laropiprant are encouraging. Further larger clinical trials are needed to better assess long-term safety and possible pleiotropic activities on clinical cardiovascular outcomes.

\section{Evidence from clinical studies on nicotinic acid-mediated antiatherosclerotic activities Lipid-modifying effects of niacin}

The beneficial effect of nicotinic acid on serum cholesterol was demonstrated for the first time 55 years ago by Altschul and coworkers [3]. A large body of clinical studies showed that therapeutic doses of nicotinic acid contribute to both improvement of lipid profile and reduction of cardiovascular and atherosclerotic outcomes (Table 1) [29-43]. Nicotinic acid has been shown to reduce circulating levels of proatherosclerotic LDL-cholesterol (LDL$\mathrm{C})$, very low density lipoprotein (VLDL)-cholesterol and lipoprotein (a) and increase the protective HDL-cholesterol (HDL-C) [44]. Niacin-mediated in vivo effects on plasma VLDL, LDL and apolipoprotein (Apo)B levels depend on two main mechanisms: the enhancement of clearance of triglyceride-rich lipoproteins containing ApoB100 and ApoB48 [45], and the decrease of production rate of VLDL [46]. On the other hand, niacin increases ApoA1 and HDL levels through different and controversial processes on the lipid profile [47]. The main mechanism of action of niacin to raise HDL levels has been indicated as a decrease in the fractional catabolic rate of $\mathrm{HDL}-\mathrm{ApoA} 1$ without affecting the synthetic rates [48]. Conversely, more recently, Lamon-Fava and coworkers showed that niacin upregulates ApoA1 production without affecting the fractional catabolic rate [45]. Furthermore, niacin induces transient inhibition of hormone-sensitive TG lipase in adipose tissue, thus reducing free fatty acid liberation, hepatic VLDL production and cholesteryl ester transfer protein (CETP)-mediated depletion of HDL. Niacin (at very high concentrations: $0.5-1 \mathrm{mM}$ ) has been shown to reduce the hepatic uptake of HDL in vitro [49,50]. Finally, niacin has been also shown to reduce the plasma levels and activity of CETP in $A P O E^{*} 3$ Leiden-transgenic mice expressing the human CETP gene [51]. In addition to HDL increase, niacin treatment could favorably influence HDL composition. Cardioprotective larger HDL particles (e.g., H5 and H4) were enhanced during niacin therapy in humans, while $\mathrm{H} 1$ particles were reduced [52,53]. The possible effect of niacin on the $\mathrm{HDL}_{2}$ subclass (which has been shown to be inversely correlated with coronary artery disease [54]) needs further experimental confirmation. Two ongoing trials (Atherothrombosis Intervention in Metabolic Syndrome with Low HDL/High Triglyceride and Impact on Global Health Outcomes [AIM-HIGH] and Treatment of HDL to Reduce the Incidence of Vascular Events [HPS2/THRIVE]) might clarify the clinical impact of niacin-mediated improvement of lipid profile in humans [55,56].

\section{Atherosclerotic surrogate \& clinical end points}

Treatment with nicotinic acid was associated with the improvement of carotid intima-media thickness (cIMT) and reduction of mortality and acute cardiovascular events. In the Coronary Drug Project (CDP; performed between 1966 and 1975) niacin treatment decreased nonfatal myocardial infarction recurrence in men with documented previous myocardial infarction. This benefit of niacin was associated with an improvement of total and LDL-C levels [29]. Importantly, in 1981 Canner and coworkers investigated the vital status for the men still alive at the end of treatment 


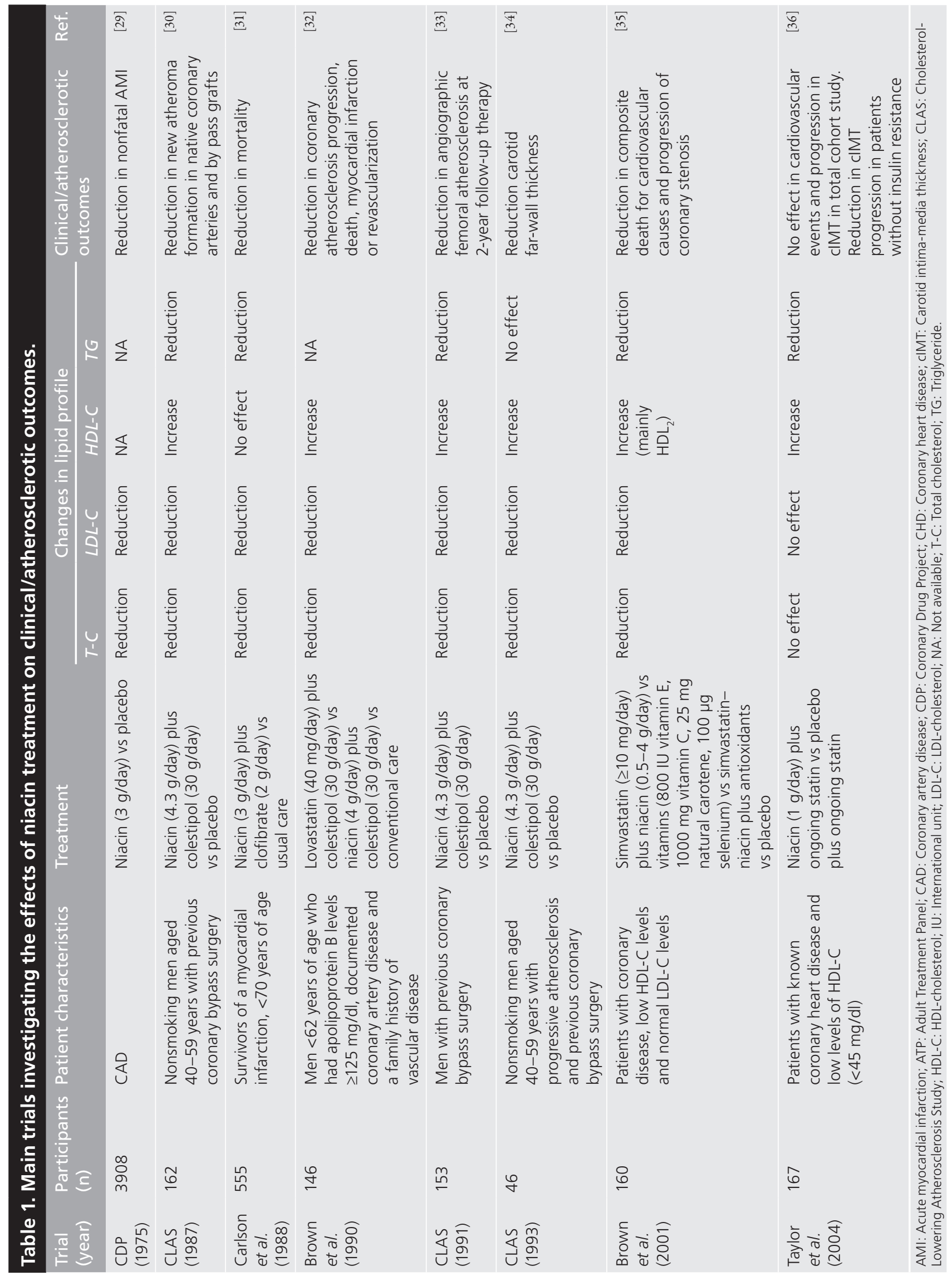




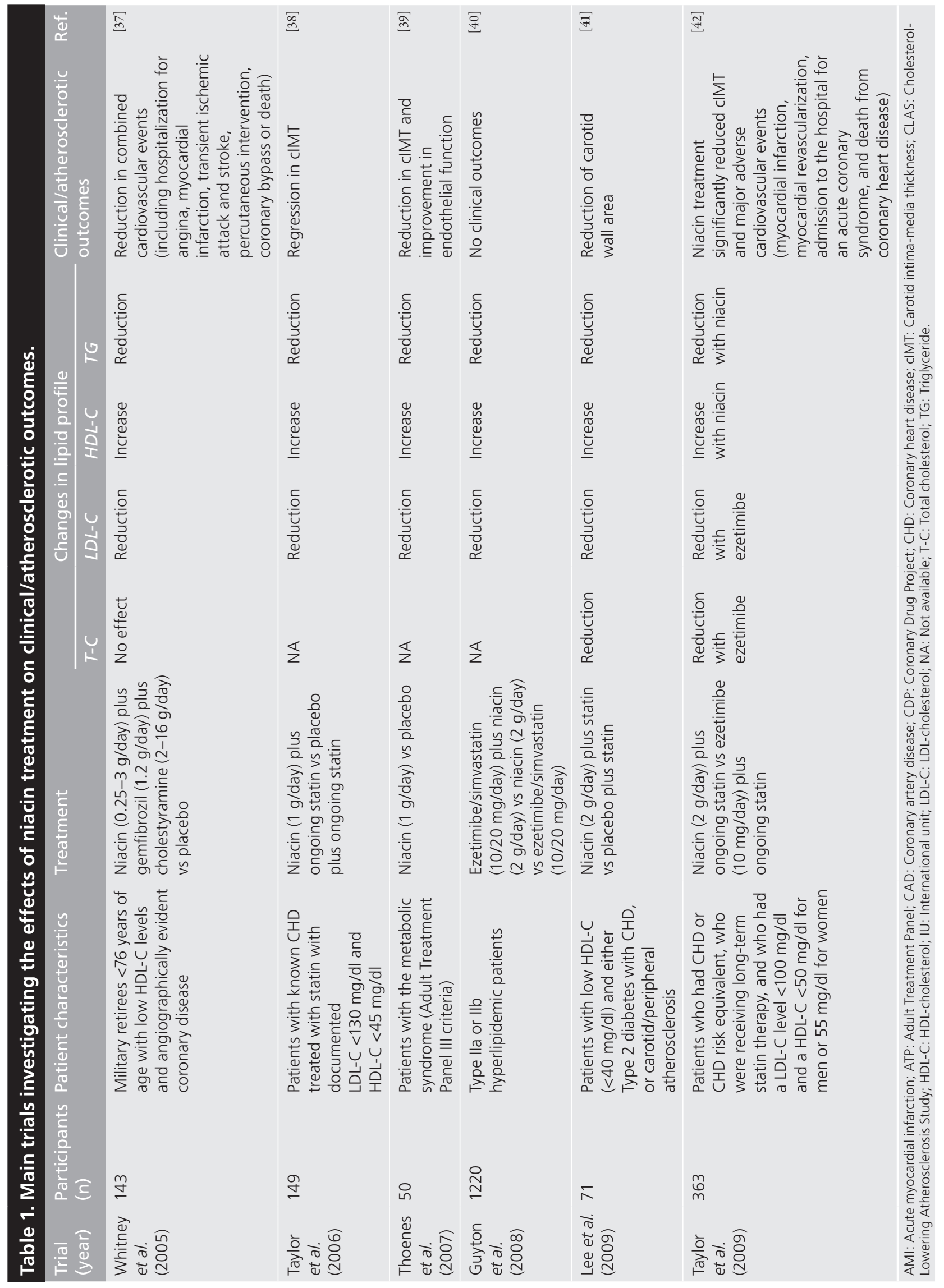


and active follow-up in 1975 [57]. Survival of patients previously treated with niacin was higher compared with the placebo group. This study investigating long-term follow-up showed that niacin treatment also had a beneficial effect after treatment interruption. The authors suggested that niacin-mediated long-term effects were probably due to its lipid-lowering property and the lower recurrence of acute myocardial infarction [57]. However, a possible direct benefit on atherosclerosis (independent of lipid-lowering properties) should not be excluded. In 1987, the CholesterolLowering Atherosclerosis Study (CLAS) focused on combined therapy with colestipol hydrochloride and niacin in a randomized placebo-controlled trial that enrolled 162 nonsmoking men aged $40-59$ years with previous coronary bypass surgery. The authors showed that during 2 years of treatment there was a $26 \%$ reduction in total plasma cholesterol, a $43 \%$ reduction in LDL-C, and a $37 \%$ elevation of HDL-C. Furthermore, a significant reduction in the average number of lesions per subject and in the percentage of subjects with new atheroma formation in native coronary arteries was observed [30]. The effect of oral niacin ( $1 \mathrm{~g} /$ day) on reducing endothelial dysfunction in patients with coronary artery disease was also investigated [58]. The authors did not observe any changes in flow-mediated dilation and nitroglycerin-mediated endotheliumindependent dilation of the brachial artery after 12-week treatment [58]. Conversely, Sorrentino and coworkers showed that HDL isolated from Type 2 diabetic patients treated with extendedrelease niacin was more protective on endothelium compared with HDL isolated from diabetic patients treated with placebo [59]. The potential role of niacin treatment in atherosclerotic inflammation was not assessed in these studies.

\section{Cardiovascular inflammatory markers}

In 2004, Taylor and coworkers investigated the levels of C-reactive protein (CRP) as a soluble parameter of atherosclerotic inflammation in a double-blind randomized placebocontrolled study enrolling 167 patients with known coronary heart disease and low levels of HDL-C $(<45 \mathrm{mg} / \mathrm{dl})$. Oncedaily extended-release niacin $(1 \mathrm{~g})$ added to background statin therapy increased HDL-C as compared with placebo. After 12 months, mean cIMT increased significantly in the placebo group $(0.044 \pm 0.100 \mathrm{~mm} ; \mathrm{p}<0.001)$ and was unchanged in the niacin group $(0.014 \pm 0.104 \mathrm{~mm} ; \mathrm{p}=0.23)$. However, the difference in cIMT between the niacin and placebo groups was not significant. More recently, Taylor and coworkers showed that niacin treatment in combination with an ongoing statin significantly reduced cIMT in patients with coronary heart disease as compared with ezetimibe/statin [42,43]. This improvement was not associated with changes in CRP serum levels. The lack of activity of niacin treatment on CRP levels was also observed as compared with placebo [36]. Accordingly, no improvement in CRP levels was shown after 24 months of treatment with niacin [38]. High-dose niacin did not reduce CRP levels in a 24-week multicenter randomized double-blind study enrolling 1220 type IIa or IIb hyperlipidemic patients [40]. In this recent study, Guyton and coworkers showed that combination therapy with niacin and ezetimibe/simvastatin 
did not improve CRP levels compared with ezetimibe/simvastin alone [40]. Therefore, there is strong evidence against a direct role of niacin in the regulation of soluble factors (such as CRP) mediating atherosclerotic inflammation. However, these data on CRP were not confirmed by Thoenes and coworkers [39]. In a randomized study enrolling patients with metabolic syndrome, the authors showed that 52 -week treatment with extended-release niacin ( $1 \mathrm{~g} /$ day) not only improved cIMT and lipid profile, but also CRP levels (reduction of $20 \% ; \mathrm{p}=0.013$ ) as compared with placebo. Surprisingly, the authors obtained a significant reduction in CRP levels despite investigating a very low number of patients [39]. The possible benefits of niacin on CRP levels have been also confirmed by Backes and coworkers [60]. In particular, the administration of a niacin-lovastatin formulation to patients with dyslipidemia has been shown to be of particular interest in reducing serum CRP [61,62]. However, as combination therapies do not represent a very useful model to investigate niacin efficacy on CRP, further clinical studies with niacin treatment alone are required. Interestingly, lowdose niacin ( $15 \mathrm{mg} /$ day) has also been recently shown to influence atherosclerotic inflammation markers. To examine the association between plasma concentrations of CRP and the intake of vitamins, Scheurig and coworkers designed a crosssectional study using data from the Monitoring of Trends and Determinants in Cardiovascular Disease/Cooperative Health Research in the Region of Augsburg (MONICA/KORA) Survey 1994/95 using samples of 2045 women and 2172 men, aged 25-74 years. Intake of dietary vitamin supplements containing niacin was associated with lower CRP levels in women, but not in men. This study also showed that intake of low doses of niacin could influence the inflammatory process underlying the pathogenesis of atherosclerosis [63]. More recently the role of niacin treatment on other cardiovascular risk markers has also been investigated. Westphal and coworkers focused on adipocytokine levels in a randomized, placebo-controlled, double-blind study enrolling 30 men with the metabolic syndrome [64]. A 6-week treatment with $1.5 \mathrm{~g} /$ day extended-release niacin was compared with placebo. Adiponectin increased by $56 \%(\mathrm{p}<0.001)$ and leptin by $26.8 \%(\mathrm{p}<0.012)$, while resistin, TNF- $\alpha$, IL- 6 and high-sensitivity CRP levels remained unaltered. Despite the low number of patients, this study showed that a short-term treatment with high-dose niacin can influence adiponectin levels [64]. Another study (enrolling only 24 patients) also confirmed niacin-mediated benefits on adiponectin levels after 10 weeks of treatment [65]. The possible anti-inflammatory effects of high doses of niacin were recently investigated in 30 patients with impaired glucose tolerance, with low HDL-C serum concentrations ( $<1.0 \mathrm{mmol} / \mathrm{l})$, but no additional comorbidities. After 6 months of daily niacin treatment, the authors compared baseline body-fat mass, insulin sensitivity and adipocytokine serum concentrations. Niacin treatment significantly increased HDL-C, adiponectin levels and whole-body insulin sensitivity and reduced the proatherosclerotic circulating lipoprotein (a) and fasting triglycerides [66]. This study confirmed the particular efficacy of high-dose niacin treatment on improving lipid profile and atherosclerotic inflammation in patients with impaired glucose tolerance or metabolic syndrome. These beneficial effects could at least in part be due to the possible pleiotropic effects of niacin in adipose tissue. In this context, Plaisance and coauthors clarified that niacin increased not only serum total concentrations of adiponectin, but also the active high-molecular weight (HMW) complex of this protein regulating important vascular anti-inflammatory and metabolic processes [67]. Although this study collected only 15 men with metabolic syndrome and treatment was performed over 6 weeks, extended-release niacin increased both serum total and HMW adiponectin concentrations, suggesting that the increase in total adiponectin concentrations observed with extended-release niacin was primarily due to an increase in the active HMW complex in obese men with metabolic syndrome [67]. Research evidence regarding the effects of niacin treatment on other emerging soluble inflammatory markers of cardiovascular risk is needed. A recent study enrolling 42 men and women with LDL-C greater than $130 \mathrm{mg} / \mathrm{dl}$ and HDL-C less than $45 \mathrm{mg} / \mathrm{dl}$ (men) or $55 \mathrm{mg} / \mathrm{dl}$ (women) showed that incremental doses of Slo-Niacin ${ }^{\circledR}$ to $1.5 \mathrm{mg} /$ day in combination with $10 \mathrm{mg} /$ day atorvastatin for 3 months improved lipoprotein lipids, apoproteins and high-sensitivity CRP without significantly decreasing circulating levels of the proinflammatory cytokines TNF- $\alpha$ and IL-6 [68]. Niacin supplementation (50 mg/day) has been shown to reduce serum cytokine levels of IL-1 $\beta$, IL-6, IL- 8 and TNF- $\alpha$ in short-term tamoxifen-treated patients with breast cancer [69]. However, this study was not designed to assess cardiovascular outcomes. Thus, the majority of these investigations did not support any association between niacin treatment and the improvement of serum levels of cardiovascular inflammatory mediators. Given the controversies probably due to the small number of patients recruited in these studies, large clinical trials based on inflammatory biomarker modification are needed.

\section{Evidence from basic research studies on nicotinic acid-mediated antiatherosclerotic activities}

The first clinical studies in humans indicated that nicotinic acid-induced benefits in atherosclerosis could be modulated by an improvement in circulating lipid profile. This crucial observation produced a great scientific effort to identify in vitro the molecular mechanisms underlying the positive impact of niacin therapy. However, recent evidence from Kashyap and coworkers showed that niacin reduced $A p o B$ secretion in culture supernatants of Hep G2 cells (human hepatoblastoma cell line) [70]. Interestingly, the authors showed that niacin-mediated benefits were due to the increase of the intracellular degradation of ApoB. One of the possible limitations of this study is represented by the dose of niacin $(0.25-3 \mathrm{mmol} / \mathrm{l})$, which was higher than pharmacologic plasma peak in vivo in humans $(0.05-0.3 \mathrm{mmol} / \mathrm{l})$ [71]. More recently, evidence from the same research group showed that niacin inhibited the activity of hepatocytes' microsomal diacylglycerol acyltransferase 2 (DGAT2; a key enzyme in triglyceride synthesis) in Hep G2 cells at a pharmacologic concentration 
$(0.05 \mathrm{mmol} / \mathrm{l})$ [72] . Both the synthetic and catabolic pathways of HDL-ApoA-I have also been investigated in vitro. Niacin has been shown to downregulate the uptake of HDL-Apo AI and the surface expression of $\beta$-chain ATP synthase in Hep G2 cells [73,74]. These studies showed that the niacin-mediated beneficial increase in HDL levels might be associated with the reduction of HDL hepatic removal through endocytosis. Less is known about the possible activation of niacin transmembrane receptors in the liver. As GPR109A and GPR109B (niacin lowaffinity receptor) are not expressed in the normal liver [7,75], further studies are needed to assess the possible regulation of niacin receptors in cardiovascular disease patients. Differently from the liver, niacin receptors seem to play a more important role in adipose tissue and inflammatory cells. In fact, GPR109A is highly expressed on these cell types and could mediate the majority of the anti-inflammatory effects of niacin. Emerging evidence from animal studies suggests that niacin receptor activation might inhibit triglyceride lipolysis in adipose tissue. In 1963, Carlson showed that niacin decreased in vitro triglyceride lipolysis in rat epididymal fat cells [76]. These data were confirmed by protein upregulated in macrophages by IFN- $\gamma$ (PUMA-G; GPR109A mouse equivalent)-deficient mouse studies, where niacin treatment failed to reduce triglyceride and free fatty acid levels in PUMA-G-deficient mice [8]. These studies clearly indicated that this receptor is essential for niacin-induced reduction of adipocyte fatty acid mobilization and triglyceride synthesis. On the other hand, niacin has also been shown to regulate other adipose tissue proinflammatory functions via its receptor. Plaisance and coworkers showed that a single administration of niacin improved serum adiponectin and nonesterified fatty acid concentrations in wild-type mice compared with placebo [77]. Importantly, these benefits were not observed in the PUMA-G knockout mice, indicating that this receptor also plays an important role in adipose tissue adiponectin secretion [77]. Nicotinic acid has also been shown to suppress the release of proatherogenic chemokines and increase the secretion of protective adiponectin in vitro (from TNF- $\alpha$-stimulated 3T3-L1 adipocytes). In this case, niacin-induced activity was mediated via GPR109A [78].

The receptor pathway has also been indicated in niacininduced regulation of immune and vascular cell functions in atherosclerosis. This novel investigation field was first described to explain the possible mechanism underlying niacin-induced flushing. Human macrophages and skin Langerhans cells have been shown in vitro to release prostaglandin $\mathrm{D}_{2}$ via GPR109A in response to niacin $[79,80]$. The pivotal role of the niacin

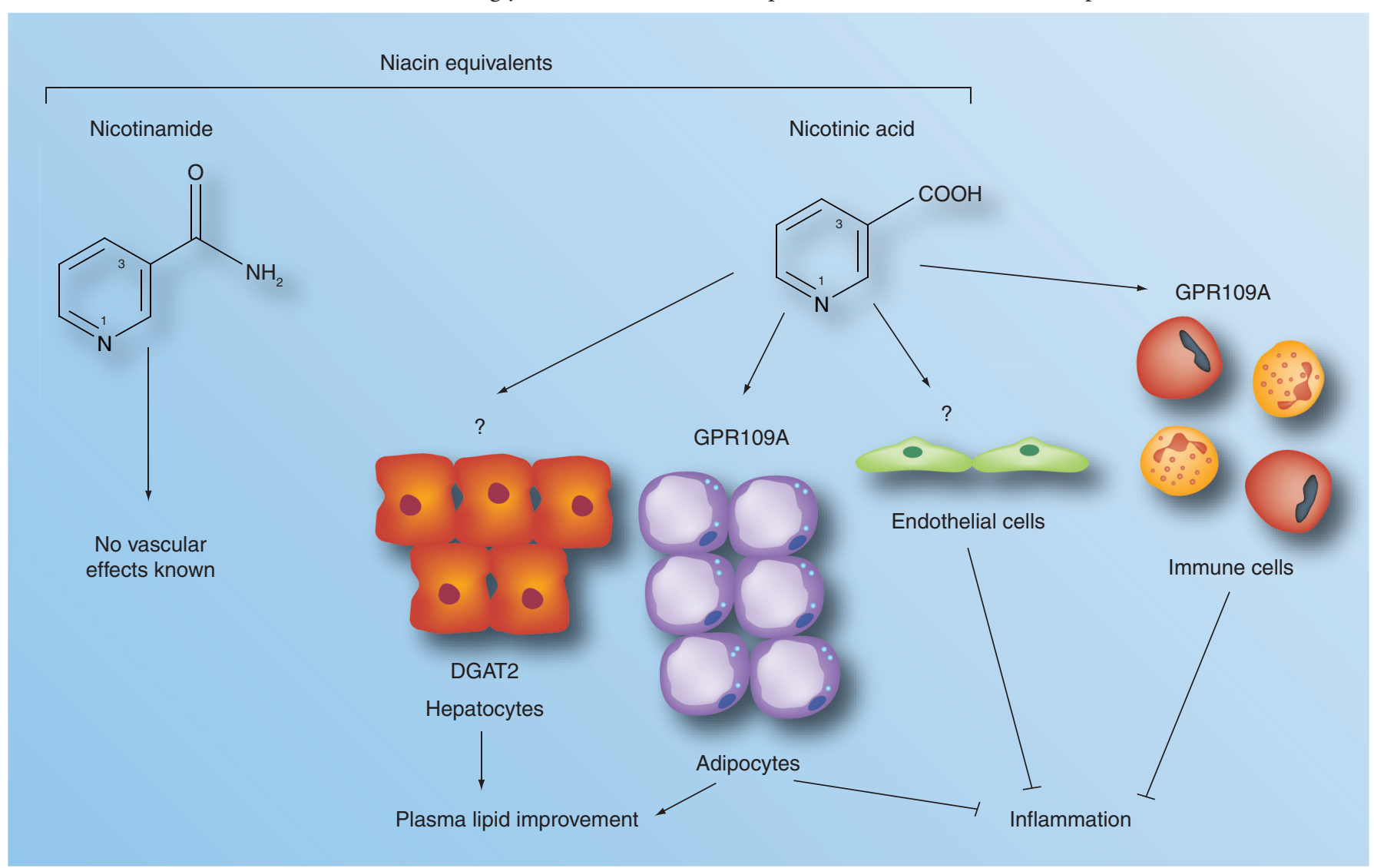

Figure 1. Nicotinic acid-mediated antiatherosclerotic activities. Among different 'niacin equivalents', only nicotinic acid (at high daily dose) has been shown to reduce atherogenesis. Nicotinic acid-mediated benefits might be dependent on plasma lipid profile improvement (mainly reduction of very low density lipoprotein, LDL and apolipoprotein-B and increase of HDL levels), and the reduction of atherosclerotic inflammation and endothelial dysfunction. Nicotinic acid modulates adipocyte and immune cell functions via its selective receptor GRP109A. Nicotinic acid molecular pathways in endothelial cells and hepatocytes are still largely unexplored. 
receptor pathway was confirmed in PUMA-G-deficient mice, showing that these mice did not develop an increase in ear blood flow during niacin treatment compared with control wildtype mice [14]. After the publication of these studies, several authors investigated niacin-mediated prostaglandin synthesis, focusing on an immunologic approach. Knowles and coworkers recently showed that pharmacological doses of niacin via its receptors induced the induction and activation of PPAR $\gamma$ in human macrophages [81]. More recently, nicotinic acid has been shown in vitro to induce human neutrophil apoptosis via GPR109A [82]. These studies indicate that immune cell functions and survival could be modulated by nicotinic acid via binding with receptor GPR109A. Further studies are needed on the role of this receptor in other inflammatory cell subsets (considered as crucial mediators in atherogenesis, such as T lymphocytes) [83,84]. More recently, a previously unknown benefit of niacin treatment has been suggested in endothelial cell dysfunction, leukocyte adhesion and oxidative stress. Wu and coworkers showed that niacin supplementation inhibited intima-media neutrophil recruitment and myeloperoxidase accumulation in an acute 'collar-induced' carotid inflammation in rabbits [85]. Accordingly, enhanced endothelial-dependent vasorelaxation was also observed. These beneficial effects were not related to plasma lipid improvements, suggesting that different pathways (i.e., niacin receptors) may mediate antiatherosclerotic effects beyond niacin's conventional role as a lipid-regulating molecule. In vitro studies of endothelial cells confirmed the reduction of reactive oxygen species production and leukocyte adhesion to niacin-treated cells $[86,87]$.

\section{Conclusion}

Basic research and clinical studies suggest a potential therapeutic role for nicotinic acid to improve lipid profile and reduce atherosclerotic inflammation. In fact, its beneficial activities are not limited to plasma lipid improvement (mainly reduction of VLDL, LDL and ApoB and increase of HDL levels), as emerging evidence indicates nicotinic acid as a promising drug to modulate inflammatory cell functions. The recent discovery of nicotinic acid receptor GPR109A has indicated new investigation fields to better understand its direct 'pleiotropic' properties (Figure 1). The possible direct activities of nicotinic acid in different inflammatory cell subtypes involved in atherosclerosis remain to be better defined. At present, the most important limitations to the clinical use of high doses of nicotinic acid is represented by its adverse effects (mainly cutaneous flushing and hepatotoxicity). In this context, the combination treatment approach with selective compounds to reduce adverse effect incidence will probably promote research efforts to evaluate niacin treatment as an anti-inflammatory drug.

\section{Expert commentary \& five-year view}

High doses (g/day) of nicotinic acid represent a very promising therapy to improve plasma lipid profile and reduce atherosclerotic clinical outcomes. In particular, clinical studies indicate that nicotinic acid reduces VLDL, LDL and ApoB levels and increases the protective HDL levels. Given the role of HDL as a potent cardiovascular protective factor, a nicotinic acid treatment approach is of particular relevance. Despite these benefits, high doses of nicotinic acid have been shown to induce remarkable adverse events (mainly cutaneous flushing and hepatotoxicity), which limited the clinical use by causing therapy discontinuation. Recently, a new combined formulation (niacin/laropiprant) has been shown to reduce the incidence of cutaneous flushing without affecting niacin antiatherosclerotic efficacy. In future, this combination strategy approach might favor the clinical management and use of nicotinic acid also in combination with statins. The possible spreading of nicotinic acid clinical use might also promote a stronger research effort to better understand its potential direct anti-inflammatory activities in atherosclerosis, independent of lipid profile amelioration. Similarly to statins, emerging evidence from basic research studies indicate that nicotinic acid reduces the release of inflammatory mediators from adipose tissue and immune cells. This pathway requires the activation of a selective transmembrane nicotinic acid receptor, GPR109A. Further molecular mechanisms (e.g., the activation of downstream intracellular pathways and the possible regulation of anti-inflammatory factors) remain unexplored and represent a very promising investigation field for cardiovascular basic scientists. Therefore, in the next few years, further rigorous and well-designed studies are required to better define a previously unknown anti-inflammatory role of the ancient drug nicotinic acid.

\section{Financial \& competing interests disclosure}

This work was funded by the 'Sir Jules Thorn Trust Reg' fund and Prévot fund to Fabrizio Montecucco. This work was funded by EU FP7, Grant number 201668, AtheroRemo and supported by grants from the Swiss National Science Foundation (\# 310030-118245), De Reuter Foundation and Boninchi Foundation to François Mach. The authors have no other relevant affiliations or financial involvement with any organization or entity with a financial interest in or financial conflict with the subject matter or materials discussed in the manuscript apart from those disclosed.

No writing assistance was utilized in the production of this manuscript.

\section{Key issues}

- Among 'niacin equivalents', only nicotinic acid treatment reduces clinical cardiovascular outcomes and improves plasma lipid profile.

- Nicotinic acid-mediated atherosclerotic protection has been shown at a high oral daily dose ( $\mathrm{g} /$ day), which has been associated with an increase of adverse events (e.g., cutaneous flushing and hepatotoxicity).

- Recent evidence from basic research suggests that nicotinic acid might directly reduce atherosclerotic inflammation via its selective receptor GPR109A.

- Further studies are needed to better evaluate the previously unexplored anti-inflammatory properties of nicotinic acid in atherosclerosis. 


\section{References}

Papers of special note have been highlighted as:

- of interest

-• of considerable interest

1 Goldberger J. The etiology of Pellagra. Public Health Rep. 29, 1683-1686 (1914).

2 Bogan KL, Brenner C. Nicotinic acid, nicotinamide, and nicotinamide riboside: a molecular evaluation of $\mathrm{NAD}^{+}$precursor vitamins in human nutrition. Annu. Rev. Nutr. 28, 115-130 (2008).

3 Altschul R, Hoffer A, Stephen JD. Influence of nicotinic acid on serum cholesterol in man. Arch. Biochem. 54(2), 558-559 (1955).

4 Damian DL. Photoprotective effects of nicotinamide. Photochem. Photobiol. Sci. 9(4), 578-585 (2010).

5 Knip M, Douek IF, Moore WP et al. European Nicotinamide Diabetes Intervention Trial Group. Safety of high-dose nicotinamide: a review. Diabetologia 43(11), 1337-1345 (2000).

6 Gille A, Bodor ET, Ahmed K, Offermanns S. Nicotinic acid: pharmacological effects and mechanisms of action. Annu. Rev. Pharmacol. Toxicol. 48, 79-106 (2008).

7 Wise A, Foord SM, Fraser NJ et al. Molecular identification of high and low affinity receptors for nicotinic acid. J. Biol. Chem. 278(11), 9869-9874 (2003).

8 Tunaru S, Kero J, Schaub A et al. PUMA-G and HM74 are receptors for nicotinic acid and mediate its anti-lipolytic effect. Nat. Med. 9(3), 352-355 (2003).

9 Soudijn W, van Wijngaarden I, Ijzerman AP. Nicotinic acid receptor subtypes and their ligands. Med. Res. Rev. 27(3), 417-433 (2007).

10 Mrochek JE, Jolley RL, Young DS, Turner WJ. Metabolic response of humans to ingestion of nicotinic acid and nicotinamide. Clin. Chem. 22(11), 1821-1827 (1976).

11 Pieper JA. Overview of niacin formulations: differences in pharmacokinetics, efficacy, and safety. Am. J. Health Syst. Pharm. 60(13 Suppl. 2), S9-S14 (2003).

12 Piepho RW. The pharmacokinetics and pharmacodynamics of agents proven to raise high-density lipoprotein cholesterol. Am. J. Cardiol. 86(12A), 35L-40L (2000).

13 Iwaki M, Ogiso T, Hayashi H, Tanino T, Benet LZ. Acute dose-dependent disposition studies of nicotinic acid in rats. Drug Metab. Dispos. 24(7), 773-779 (1996).
14 Benyó Z, Gille A, Kero J et al. GPR109A (PUMA-G/HM74A) mediates nicotinic acid-induced flushing. J. Clin. Invest. 115(12), 3634-3640 (2005).

15 Morgan JM, Capuzzi DM, Guyton JR. A new extended-release niacin (Niaspan): efficacy, tolerability, and safety in hypercholesterolemic patients. Am. J. Cardiol. 82(12A), 29U-34U (1998).

16 Carlson LA. Niaspan, the prolonged release preparation of nicotinic acid (niacin), the broad-spectrum lipid drug. Int. J. Clin. Pract. 58(7), 706-713 (2004).

17 McCormack PL, Keating GM. Prolonged-release nicotinic acid: a review of its use in the treatment of dyslipidaemia. Drugs 65(18), 2719-2740 (2005).

18 Shepherd J, Betteridge J, Van Gaal L; European Consensus Panel. Nicotinic acid in the management of dyslipidaemia associated with diabetes and metabolic syndrome: a position paper developed by a European Consensus Panel. Curr. Med. Res. Opin. 21(5), 665-682 (2005).

19 McKenney J. New perspectives on the use of niacin in the treatment of lipid disorders. Arch. Intern. Med. 164(7), 697-705 (2004).

20 Chapman MJ, Redfern JS, McGovern ME, Giral P. Niacin and fibrates in atherogenic dyslipidemia: pharmacotherapy to reduce cardiovascular risk. Pharmacol. Ther. 126(3), 314-345 (2010).

21 Menon RM, González MA, Adams MH, Tolbert DS, Leu JH, Cefali EA. Effect of the rate of niacin administration on the plasma and urine pharmacokinetics of niacin and its metabolites. J. Clin. Pharmacol. 47(6), 681-688 (2007).

22 Sturino CF, O'Neill G, Lachance N et al. Discovery of a potent and selective prostaglandin D2 receptor antagonist, [(3R)-4-(4-chloro-benzyl)-7-fluoro-5(methylsulfonyl)-1,2,3,4tetrahydrocyclopenta[b] indol-3-yl]-acetic acid (MK-0524).J. Med. Chem. 50 (4), 794-806 (2007).

23 Cheng K, Wu TJ, Wu KK et al. Antagonism of the prostaglandin D2 receptor 1 suppresses nicotinic acidinduced vasodilation in mice and humans. Proc. Natl Acad. Sci. USA 103(17), 6682-6687 (2006).

24 Lai E, De Lepeleire I, Crumley TM et al. Suppression of niacin-induced vasodilation with an antagonist to prostaglandin D2 receptor subtype 1. Clin. Pharmacol. Ther. 81(6), 849-857 (2007).
25 Paolini JF, Mitchel YB, Reyes R et al. Effects of laropiprant on nicotinic acid-induced flushing in patients with dyslipidemia. Am. J. Cardiol. 101(5), 625-630 (2008).

26 Maccubbin D, Bays HE, Olsson AG et al. Lipid-modifying efficacy and tolerability of extended-release niacin/laropiprant in patients with primary hypercholesterolaemia or mixed dyslipidaemia. Int. J. Clin. Pract. 62(12), 1959-1970 (2008).

27 Paolini JF, Bays HE, Ballantyne CM et al. Extended-release niacin/laropiprant: reducing niacin-induced flushing to better realize the benefit of niacin in improving cardiovascular risk factors. Cardiol. Clin. 26(4), 547-560 (2008).

28 Gleim G, Ballantyne CM, Liu N et al. Efficacy and safety profile of coadministered ER niacin/laropiprant and simvastatin in dyslipidaemia. Br. J. Cardiol. 16, 90-97 (2009).

29 Clofibrate and niacin in coronary heart disease. JAMA 231(4), 360-381 (1975).

- One of the most important clinical studies on niacin treatment.

30 Blankenhorn DH, Nessim SA, Johnson RL, Sanmarco ME, Azen SP, CashinHemphill L. Beneficial effects of combined colestipol-niacin therapy on coronary atherosclerosis and coronary venous bypass grafts. JAMA 257(23), 3233-3240 (1987).

31 Carlson LA, Rosenhamer G. Reduction of mortality in the Stockholm Ischaemic Heart Disease Secondary Prevention Study by combined treatment with clofibrate and nicotinic acid. Acta Med. Scand. 223(5), 405-418 (1988).

32 Brown G, Albers JJ, Fisher LD et al. Regression of coronary artery disease as a result of intensive lipid-lowering therapy in men with high levels of apolipoprotein B. N. Engl. J. Med. 323(19), 1289-1298 (1990).

33 Blankenhorn DH, Azen SP, Crawford DW et al. Effects of colestipol-niacin therapy on human femoral atherosclerosis. Circulation 83(2), 438-447 (1991).

34 Blankenhorn DH, Selzer RH, Crawford DW et al. Beneficial effects of colestipolniacin therapy on the common carotid artery. Two- and four-year reduction of intima-media thickness measured by ultrasound. Circulation 88(1), 20-28 (1993).

35 Brown BG, Zhao XQ, Chait A et al. Simvastatin and niacin, antioxidant vitamins, or the combination for the prevention of coronary disease. N. Engl. J. Med. 345(22), 1583-1592 (2001). 
36 Taylor AJ, Sullenberger LE, Lee HJ, Lee JK, Grace KA. Arterial Biology for the Investigation of the Treatment Effects of Reducing Cholesterol (ARBITER) 2: a double-blind, placebo-controlled study of extended-release niacin on atherosclerosis progression in secondary prevention patients treated with statins. Circulation 110(23), 3512-3517 (2004).

37 Whitney EJ, Krasuski RA, Personius BE et al. A randomized trial of a strategy for increasing high-density lipoprotein cholesterol levels: effects on progression of coronary heart disease and clinical events. Ann. Intern. Med. 142(2), 95-104 (2005).

38 Taylor AJ, Lee HJ, Sullenberger LE. The effect of 24 months of combination statin and extended-release niacin on carotid intima-media thickness: ARBITER 3. Curr. Med. Res. Opin. 22(11), 2243-2250 (2006).

39 Thoenes M, Oguchi A, Nagamia $S$ et al. The effects of extended-release niacin on carotid intimal media thickness, endothelial function and inflammatory markers in patients with the metabolic syndrome. Int. J. Clin. Pract. 61(11), 1942-1948 (2007).

40 Guyton JR, Brown BG, Fazio S, Polis A, Tomassini JE, Tershakovec AM. Lipidaltering efficacy and safety of ezetimibe/ simvastatin coadministered with extendedrelease niacin in patients with type IIa or type IIb hyperlipidaemia. J. Am. Coll. Cardiol. 51(16), 1564-1572 (2008).

41 Lee JM, Robson MD, Yu LM et al. Effects of high-dose modified-release nicotinic acid on atherosclerosis and vascular function: a randomized, placebo-controlled, magnetic resonance imaging study. J. Am. Coll. Cardiol. 54(19), 1787-1794 (2009).

42 Taylor AJ, Villines TC, Stanek EJ et al. Extended-release niacin or ezetimibe and carotid intima-media thickness. N. Engl. J. Med. 361(22), 2113-2122 (2009).

- Another important clinical study on niacin treatment.

43 Villines TC, Stanek EJ, Devine PJ et al. The ARBITER 6-HALTS Trial (Arterial Biology for the Investigation of the Treatment Effects of Reducing Cholesterol 6-HDL and LDL Treatment Strategies in Atherosclerosis) final results and the impact of medication adherence, dose, and treatment duration. J. Am. Coll. Cardiol. 55(24), 2721-2726 (2010).

44 Digby JE, Lee JM, Choudhury RP. Nicotinic acid and the prevention of coronary artery disease. Curr. Opin. Lipidol. 20(4), 321-326 (2009).
45 Lamon-Fava S, Diffenderfer MR, Barrett $\mathrm{PH}$ et al. Extended-release niacin alters the metabolism of plasma apolipoprotein (Apo) A-I and ApoB-containing lipoproteins. Arterioscler. Thromb. Vasc. Biol. 28(9), 1672-1678 (2008).

46 Wang W, Basinger A, Neese RA et al. Effect of nicotinic acid administration on hepatic very low density lipoprotein-triglyceride production. Am. J. Physiol. Endocrinol. Metab. 280 (3), E540-E547 (2001).

47 Chapman MJ, Le Goff W, Guerin M, Kontush A. Cholesteryl ester transfer protein: at the heart of the action of lipid-modulating therapy with statins, fibrates, niacin, and cholesteryl ester transfer protein inhibitors. Eur. Heart J. 31(2), 149-164 (2010).

48 Ganji SH, Kamanna VS, Kashyap ML. Niacin and cholesterol: role in cardiovascular disease (review). J. Nutr. Biochem. 14(6), 298-305 (2003).

4 Zhang LH, Kamanna VS, Zhang MC, Kashyap ML. Niacin inhibits surface expression of ATP synthase $\beta$ chain in HepG 2 cells: implications for raising HDL. J. Lipid. Res. 49(6), 1195-1201 (2008).

50 Kamanna VS, Kashyap ML. Mechanism of action of niacin. Am. J. Cardiol. 101(8A), 20B-26B (2008).

51 van der Hoorn JW, de Haan W, Berbé JF et al.. Niacin increases HDL by reducing hepatic expression and plasma levels of cholesteryl ester transfer protein in APOE*3Leiden.CETP mice. Arterioscler. Thromb. Vasc. Biol. 28(11), 2016-2022 (2008).

52 Guyton JR, Blazing MA, Hagar J et al. Extended-release niacin vs gemfibrozil for the treatment of low levels of high-density lipoprotein cholesterol. NiaspanGemfibrozil Study Group. Arch. Intern. Med. 160(8), 1177-1184 (2000).

53 Morgan JM, Capuzzi DM, Baksh RI et al. Effects of extended-release niacin on lipoprotein subclass distribution. Am. J. Cardiol. 91(12), 1432-1436 (2003).

54 Johansson J, Carlson LA, Landou C, Hamsten A. High density lipoproteins and coronary atherosclerosis. A strong inverse relation with the largest particles is confined to normotriglyceridemic patients. Arterioscler. Thromb. 11(1), 174-182 (1991).

55 Windler E, Schöffauer M, Zyriax BC. The significance of low HDL-cholesterol levels in an ageing society at increased risk for cardiovascular disease. Diab. Vasc. Dis. Res. 4(2), 136-142 (2007).
56 Preiss D, Sattar N. Lipids, lipid modifying agents and cardiovascular risk: a review of the evidence. Clin. Endocrinol. (Oxf.). 70(6), 815-828 (2009).

57 Canner PL, Berge KG, Wenger NK et al. Fifteen year mortality in Coronary Drug Project patients: long-term benefit with niacin. J. Am. Coll. Cardiol. 8(6), 1245-1255 (1986).

58 Warnholtz A, Wild P, Ostad MA et al. Effects of oral niacin on endothelial dysfunction in patients with coronary artery disease: results of the randomized, double-blind, placebo-controlled INEF study. Atherosclerosis 204(1), 216-221 (2009).

59 Sorrentino SA, Besler C, Rohrer L et al. Endothelial-vasoprotective effects of high-density lipoprotein are impaired in patients with Type 2 diabetes mellitus but are improved after extended-release niacin therapy. Circulation 121(1), 110-122 (2010).

60 Backes JM, Howard PA, Moriarty PM. Role of C-reactive protein in cardiovascular disease. Ann. Pharmacother. 38, 110-118 (2004).

61 Kashyap ML, McGovern ME, Berra K et al. Long-term safety and efficacy of a once-daily niacin/lovastatin formulation for patients with dyslipidemia. Am. J. Cardiol. 89, 672-678 (2002).

62 Moon YS, Kashyap ML. Niacin extendedrelease lovastatin: combination therapy for lipid disorders. Expert Opin. Pharmacother. 3, 1768-1774 (2002).

63 Scheurig AC, Thorand B, Fischer B, Heier $\mathrm{M}$, Koenig W. Association between the intake of vitamins and trace elements from supplements and C-reactive protein: results of the MONICA/KORA Augsburg study. Eur. J. Clin. Nutr. 62(1), 127-137 (2008).

64 Westphal S, Borucki K, Taneva E, Makarova R, Luley C. Extended-release niacin raises adiponectin and leptin. Atherosclerosis 193(2), 361-365 (2007).

65 Westphal S, Borucki K, Taneva E, Makarova R, Luley C. Adipokines and treatment with niacin. Metabolism 55(10), 1283-1285 (2006).

66 Linke A, Sonnabend M, Fasshauer M et al Effects of extended-release niacin on lipid profile and adipocyte biology in patients with impaired glucose tolerance. Atherosclerosis 205(1), 207-213 (2009).

67 Plaisance EP, Grandjean PW, Brunson BL, Judd RL. Increased total and highmolecular weight adiponectin after extended-release niacin. Metabolism 57(3), 404-409 (2008). 
68 Knopp RH, Retzlaff BM, Fish B et al. The SLIM Study: Slo-Niacin ${ }^{\circledR}$ and Atorvastatin Treatment of Lipoproteins and Inflammatory Markers in Combined Hyperlipidemia. J. Clin. Lipidol. 3(3), 167-178 (2009).

69 Premkumar VG, Yuvaraj S, Vijayasarathy K, Gangadaran SG, Sachdanandam P. Serum cytokine levels of interleukin-1 $\beta,-6,-8$, tumour necrosis factor- $\alpha$ and vascular endothelial growth factor in breast cancer patients treated with tamoxifen and supplemented with co-enzyme Q(10), riboflavin and niacin. Basic Clin. Pharmacol. Toxicol. 100(6), 387-391 (2007).

70 Jin FY, Kamanna VS, Kashyap ML. Niacin accelerates intracellular ApoB degradation by inhibiting triacylglycerol synthesis in human hepatoblastoma (HepG2) cells. Arterioscler. Thromb. Vasc. Biol. 19(4), 1051-1059 (1999).

71 Kamanna VS, Kashyap ML. Nicotinic acid (niacin) receptor agonists: will they be useful therapeutic agents? Am. J. Cardiol. 100(11 A), S53-S61 (2007).

72 Ganji SH, Tavintharan S, Zhu D, Xing Y, Kamanna VS, Kashyap ML. Niacin noncompetitively inhibits DGAT2 but not DGAT1 activity in HepG2 cells. J. Lipid. Res. 45(10), 1835-1845 (2004).

73 Jin FY, Kamanna VS, Kashyap ML. Niacin decreases removal of high-density lipoprotein apolipoprotein A-I but not cholesterol ester by Hep G2 cells. Implication for reverse cholesterol transport. Arterioscler. Thromb. Vasc. Biol. 17(10), 2020-2028 (1997).

74 Zhang LH, Kamanna VS, Zhang MC, Kashyap ML. Niacin inhibits surface expression of ATP synthase $\beta$ chain in
HepG2 cells: implications for raising HDL. J. Lipid. Res. 49(6), 1195-1201 (2008).

75 Soga T, Kamohara M, Takasaki J et al. Molecular identification of nicotinic acid receptor. Biochem. Biophys. Res. Commun. 303(1), 364-369 (2003).

76 Carlson LA. Studies on the effect of nicotinic acid on catecholamine stimulated lipolysis in adipose tissue in vitro. Acta. Med. Scand. 173, 719-722 (1963).

77 Plaisance EP, Lukasova M, Offermanns S, Zhang Y, Cao G, Judd RL. Niacin stimulates adiponectin secretion through the GPR109A receptor. Am. J. Physiol. Endocrinol. Metab. 296(3), E549-E558 (2009).

78 Digby JE, McNeill E, Dyar OJ, Lam V, Greaves DR, Choudhury RP. Antiinflammatory effects of nicotinic acid in adipocytes demonstrated by suppression of fractalkine, RANTES, and MCP-1 and upregulation of adiponectin. Atherosclerosis 209(1), 89-95 (2010).

79 Maciejewski-Lenoir D, Richman JG et al. Langerhans cells release prostaglandin D2 in response to nicotinic acid. J. Invest. Dermatol. 126(12), 2637-2646 (2006).

80 Meyers CD, Liu P, Kamanna VS, Kashyap ML. Nicotinic acid induces secretion of prostaglandin D2 in human macrophages: an in vitro model of the niacin flush. Atherosclerosis 192(2), 253-258 (2007).

81 Knowles HJ, te Poele RH, Workman P, Harris AL. Niacin induces PPAR $\gamma$ expression and transcriptional activation in macrophages via HM74 and HM74amediated induction of prostaglandin synthesis pathways. Biochem. Pharmacol. 71(5), 646-656 (2006).
82 Kostylina G, Simon D, Fey MF, Yousefi S, Simon HU. Neutrophil apoptosis mediated by nicotinic acid receptors (GPR109A). Cell Death Differ. 15(1), 134-142 (2008).

83 Carson DA, Seto S, Wasson DB. Pyridine nucleotide cycling and poly(ADPribose) synthesis in resting human lymphocytes. J. Immunol. 138(6), 1904-1907 (1987).

84 Weber C, Zernecke A, Libby P. The multifaceted contributions of leukocyte subsets to atherosclerosis: lessons from mouse models. Nat. Rev. Immunol. 8(10), 802-815 (2008).

85 Wu BJ, Yan L, Charlton F, Witting P, Barter PJ, Rye KA. Evidence that niacin inhibits acute vascular inflammation and improves endothelial dysfunction independent of changes in plasma lipids. Arterioscler. Thromb. Vasc. Biol. 30(5), 968-975 (2010).

- Demonstrates that nicotinic acid can inhibit vascular inflammation induced in a periarterial carotid collar model, resulting in reduced endothelial dysfunction.

86 Ganji SH, Qin S, Zhang L, Kamanna VS, Kashyap ML. Niacin inhibits vascular oxidative stress, redox-sensitive genes, and monocyte adhesion to human aortic endothelial cells. Atherosclerosis 202(1), 68-75 (2009).

87 Tavintharan S, Lim SC, Sum CF. Effects of niacin on cell adhesion and early atherogenesis: biochemical and functional findings in endothelial cells. Basic Clin. Pharmacol. Toxicol. 104(3), 206-210 (2009). 